\title{
Teachers' Perceptions about the Use of Background Music in Preschool Free Play Time
}

Youngae Lee ${ }^{1)}$

Korea National Open University

\author{
Graham F. Welch
}

University College London

\begin{abstract}
The allocation of free-play time in an early childhood curriculum provides opportunities for child-centred learning and gives children a chance to explore safely the world around them. However, previous literature suggests that the beneficial use background music during free-play time is contested and that further research would be useful. A specially designed survey was sent to teachers in Seoul, Kyoung-gi, and Choong-chung provinces in South Korea by e-mail and supplemented post-survey by $n=12$ in-depth interviews. Data from $n=127$ surveys were gathered for final analyses. The responses were divided into two main categories: the case for the use of background music during free-play time and the case against. The numbers of teachers in each category were similar. $54 \%$ of teachers reported using background music for children's free-play time and transitions, both in accordance with children's preferences and also to facilitate a musical sound environment for children's play; however, $46 \%$ of teachers did not use background music because of a perception that it would create noise problems in the classroom. Selected background music tended to be of medium tempi, with or without lyrics, often calm and quiet, with medium or soft dynamics. Music choices related to the perceived mood of the music, children's perceived preferences, and the music's relationships to a chosen educational theme. The majority of teachers who used background music during free-play time reported that this was also helpful in the learning of songs or to support content-related curricular themes.
\end{abstract}

Keywords: background music, early childhood music education, free-play time, play, preschool

Corresponding author, ${ }^{1)}$ yaelee@knou.ac.kr 
Young children learn by interaction with, and through experience of, their environment, both in general (Bredekamp \& Copple, 1997) and also in relation to music (Young 2016). Learning is also moderated by maturational and developmental processes (Adachi \& Trehub, 2012; Tronick, 2007; Welch, 2006). For young children, spontaneous play is commonly regarded as a most effective way of learning and provides rich opportunities to consolidate current and earlier experience. Consequently, time needs to be set aside for play when young children enter pre-school, as well as at home. Playing provides children with opportunities for physical, language, social, emotional and cognitive development and supports physical and psychological well-being (Kenneth, 2007; Barrett, 2016). In particular, positive peer interaction during play time is reported to be related to psychological stability and academic achievement in later school life (Jung \& Ahn, 2006). The allocation of free-play time in an early childhood curriculum provides opportunities for child-centred learning and gives children a chance to explore safely the world around them. Young children can experience opportunities to plan and choose the activity that they want to pursue. Nevertheless, there are reports that free-play time in South Korea pre-school education has decreased recently due to parental demands for specific educational activities, such as special lessons, field trips, and English classes (Kim \& Lee, 2005; Song, 2010). To counter this, the South Korean National Curriculum, Nuri-curriculum, has strongly recommended that teachers should guarantee at least one hour for free-play each day ( Ministry of Education \& Ministry of Health and Welfare,2013), but this guarantee of sufficient free-play time for young children continues to be threatened by special classes and events. Despite these challenges, the management of free-play time efficiently is an important role for the teacher. Music has been one of various strategies to manage this time effectively during the daily schedule in the preschools, such as in the transitions between schedules, and as a signal for specific moments in the school (e.g., time for free-play and lunch) (Lee, 2008).

In this context, background music refers to music played at a soft volume (under $60 \mathrm{~dB}$ ) during other activities (Godeli, Santana, Souza, \& Marquetti, 1996; Rauscher, Shaw, \& Ky, 1993a). Several researchers have reported an interest in the use of background music for free-play time in early childhood institutions (e.g., Gruhn \& Rauscher, 2002; Hallam, Price \& Katasrou, 2002; Love \& Burns, 2007; Mattar, 2013; Riber, 1965). Background music is 
reported to facilitate socially constructive and sociodramatic play (Love \& Burns, 2007), positive child-to-child interactions (Godeli et al.1996) and to have a positive influence on aspects of children's cognition, including mathematics test scores (Rauscher, Shaw, \& Ky, 1993b). Some studies of older children's reading performances indicated the positive effect of background music (Carlson, Hoffman, Gray, \& Thompson, 2004; Schellenberg, Nakata, Hnter, \& Tamoto, 2007), whilst others report a negative effect (Anderson \& Fuller, 2010; Avila, Furnham \& McClelland, 2011; Boyle \& Coltheart, 1996), or no significant difference concerning whether music was being played in the background or not (Johansson, Holmqvist, Mossberg \& Lindgren, 2011).

Besides the possible cognitive effects, previous studies have reported the emotional function of music. Hallam et al. (2002), for example, suggested that music's reported effects are mediated by their impact on levels of arousal and emotional state rather than affecting cognition directly. Also, music is reported to induce universal emotional arousal (Egermann, Fernando, Chuen, \& McAdams, 2015) and influence mood (Eich \& Forgas, 2003; Saarikallio, 2008). In a similar line, Ziv \& Goshen (2006) found that background music affected five- to six year-old children's interpretation of stories in terms of emotion, such as happy and sad.

Due to such effects, previous studies have reported background music as being used in various ways. These include the transitioning between activities, to introducing new songs, naptime, mealtimes, and to help to present new concepts, as well as either to calm or energize the children (Lee, 2008; Sims \& Cecconi-Roberts, 2005). Also, many teachers have intentionally used music in four ways: to relax; to invigorate; to focus student attention; or to ease transitions (Campbell, Campbell \& Dickinson, 2004).

According to previous studies about the $\mathrm{CD}$ collections that teachers use in preschools (including use as background music), the nature of the musical content can vary considerably —as might be expected — and is related to local context. For example, Sims and Cecconi-Roberts (2005) investigated CD collections in preschools in the mid-West area of the U.S. and indicated that teachers mostly used music written specifically for children and also popular music, such as jazz and pop CDs. Lee's (2008) study in South Korea indicated that surveyed teachers mostly used children's song collections in preschools across thirteen provinces. 
The choice of musical content could be significant, given that there are studies that popular music can interfere with complex tasks and reading comprehension (e.g., Anderson \& Fuller, 2010; Avila et al, 2011; Johansson et al, 2011). In a related study, Darrt (2009) investigated the effect of background music in preschools to determine whether this increased the focused attention of 4- and 5-year-olds during solitary play. The results indicated that preschoolers had less focused attention when Western Classical music was played in the background.

Furthermore, background music in the classroom may interrupt children's play and also impact negatively on the teachers' work environment. For example, Grebennikov (2006) revealed that teachers were exposed to daily noise in the classroom and music was reported to be one of the noise sources. Other studies have indicated that school design type and acoustic environment affect teachers' perceived noise exposure (Connolly, Dockerell, Shield, Conetta, \& Cox, 2013; Kristiansen, et al, 2016; Shield, Greenland \& Dockrell, 2010). In particular, pre-school settings are reported to be relatively noisy work environments, with noise levels often above recommended hearing thresholds (Golden \& Frank, 2000; Sodersten, Granqvist, Hammarberg, \& Szabo, 2002).

Given these differences in reported findings on the effects of background music, it seems that such music may have both positive and negative impacts. However, there appears to have been very little (if any) research to investigate the effect of background music in free-play situations, and there has been limited research about the actual conditions and teachers' perceptions about the use or not of background music, such as in early years' settings. Although there have been studies on preschools' music practices, children's singing in free-play contexts (Young, 2002), musical environments, and play types in free-play time, there has been no study regarding the proportions of teachers who use background music, nor why they do or do not use it.

This article reports an investigation into the use of background music in free-play time in preschools of South Korea. The study sought to answer the following three research questions:

1. What percentage of teachers use background music during free-play time in preschools in South Korea?

2. Why do teachers choose to use (or not use) background music during free-play time in 
preschools in South Korea?

3. How is background music used during free-play time in preschools in South Korea?

\section{Method}

\section{Design}

Background: This study started from the author's observations of free-play time in preschools. Similar to the assessment schedule visits of the Office for Standards in Education, Children's Services and Skills (Ofsted) in England, South Korea has a national assessment system for all public and private preschools every three years. As an investigator for preschool assessment, the author had visited and observed fourteen public and private preschools and, at that time, it was clear that some preschools used background music during free-play time, but some did not. The author interviewed teachers informally about their reasons for using background music in the classroom, but their answers were not uniform and so the author decided to examine the phenomenon in more detail, such as how many preschools used background music, their reasons for doing so (or not), and whether there were differences between kindergarten and daycare centres.

Two main methods were adopted: (a) an anonymous on-line survey questionnaire and, separately, (b) interviews with a small number of preschool teachers.

(a) The on-line survey questions were based on the comments from the earlier teachers' informal interviews about the use of background music in their classrooms. To strengthen the content validity of the research instrument, the draft questionnaire was reviewed by two professors in early childhood education and three preschool teachers. The survey was conducted anonymously. All teachers participated with knowledge of the characteristics of this study, such as confidentiality and the lack of consequences for nonparticipation. The survey would take 20 to 30 minutes to complete. In order to prevent double participation, a system was employed to ensure that no more than one response came from any single Internet Protocol address.

The questionnaire was divided in three sections, including teachers' demographic information, use of background music in free-play contexts or not and their reasons, 
and - if used - more information on the detail of use. The questionnaire design had two main investigative sections: the case for use of background music and the case against. The survey consisted of single- and multiple- choice responses with Likert-type scales (very important $=1$; not at all $=5$ ). In terms of how teachers used background music, the questionnaire sought information on the music sources, music genres, devices for playing, and music styles - including tempo, mood and loudness. Since the purpose of study was to understand teachers' perception on the use of background music, music style characteristics were based on teachers' interpretation of these commonplace terms (tempo, mood and loudness) rather than using musical terms such as moderato, presto, forte or piano.

(b) Subsequent to the survey, interviews were undertaken with a small number of preschool teachers, chosen to offer a range of contrasting backgrounds (daycare and kindergarten) and contexts, and to provide more detail of the views on the use of background music. The participants were twelve teachers working in preschool contexts, including Montessori kindergarten, private kindergarten and daycare centres in Seoul. Their teaching experience ranged from 2 to 13 years. The interview data revealed that none of these interview participants had previously undertaken the online questionnaire.

\section{Participants}

This study was designed to survey preschool teachers in South Korea in order to investigate their use (or not) of background music in free-play time in preschools and their stated reasons for their answers. In South Korea, early childhood institutions are divided into two main categories: (a) kindergarten, which are under the Ministry of Education and (b) daycare centres, which are under the Ministry of Health and Welfare. A kindergarten is for three- to five-year-olds, whereas a daycare centre is for children aged from birth to 5 years. Kindergarten may be either public or private. Daycare centres may be public or private, company run, or home-based. There has been a political effort to promote greater unity of experience in kindergarten and daycare centres and this has continued for over thirty years (Lee, 2015; Chi, Hong, Lee, \& Chang, 2015). As a result of these efforts, a unified early years national curriculum for three- to five-year-olds was enacted in 2013 (Ministry of Education \& Ministry of Health and Welfare, 2013).

The participants in this study were from both main types of institutions, kindergarten and 
daycare centres. The survey was sent by email to 200 teachers in the Seoul, Kyoung-gi, and Choong-chung provinces in South Korea. The survey was sent to only one teacher in each school, drawn from an institutional data pool, in order to gather a widespread dataset. Data from $\mathrm{n}=127$ surveys ( $63.5 \%$ acceptance rate) were received and examined for subsequent

Table 1. Demographic Summary of Study Participants

\begin{tabular}{|c|c|c|}
\hline Categories & Content & $N(\%)$ \\
\hline \multirow{5}{*}{$\begin{array}{l}\text { Teachers' age } \\
\text { ranges in years }\end{array}$} & $20-24$ & $5(4)$ \\
\hline & $25-29$ & $23(18)$ \\
\hline & $30-34$ & $21(17)$ \\
\hline & $35-39$ & $24(19)$ \\
\hline & $40-45$ & $54(43)$ \\
\hline \multirow{5}{*}{$\begin{array}{c}* \text { Professional } \\
\text { certification level }\end{array}$} & Kindergarten level I and above & $36(28)$ \\
\hline & Kindergarten level II & $89(70)$ \\
\hline & Daycare level I and above & $72(57)$ \\
\hline & Daycare level II & $25(20)$ \\
\hline & Daycare level III & $1(1)$ \\
\hline \multirow{5}{*}{$\begin{array}{c}\text { Teaching experience, } \\
\text { years }\end{array}$} & $<1$ & $8(6)$ \\
\hline & $1-<3$ & $14(11)$ \\
\hline & $>3-<5$ & $20(16)$ \\
\hline & $>5-<10$ & $34(27)$ \\
\hline & $10+$ & $51(40)$ \\
\hline \multirow{5}{*}{$\begin{array}{l}\text { Type of workplace } \\
\text { institution }\end{array}$} & Public kindergarten & $25(20)$ \\
\hline & Private kindergarten & $45(35)$ \\
\hline & Public daycare centres & $19(15)$ \\
\hline & Private daycare centres & $25(20)$ \\
\hline & Home-based daycare centres & $13(10)$ \\
\hline \multirow{7}{*}{$\begin{array}{l}\text { Age group(s) of } \\
\text { children in the } \\
\text { classrooms, in years }\end{array}$} & $<12$ months & $8(6)$ \\
\hline & 1 & $12(9)$ \\
\hline & 2 & $19(15)$ \\
\hline & 3 & $15(12)$ \\
\hline & 4 & $18(14)$ \\
\hline & 5 & $37(29)$ \\
\hline & Mixed age group & $18(14)$ \\
\hline
\end{tabular}

* The response about professional certificate was multiple choice, since teachers could have more than one type of certification. 
analysis. Table 1 presents the general background of the participants. In general, two-thirds of respondents tended to be older (aged 35+ years), holding a range of professional certification, with significant teaching experience ( 5 years + ), and representing a range of workplace settings and experience with different ages of children, particularly in the range 3-5 years. The official professional certification level in South Korea is labelled such that lower numbers indicate a higher level of award, i.e., Level I > Level II.

Table 2. Survey Questions by Category

\begin{tabular}{llc}
\hline \multicolumn{1}{c}{ Categories } & \multicolumn{1}{c}{ Content } & $\begin{array}{c}\text { Question } \\
\text { numbers }\end{array}$ \\
\hline Demographic information & General and professional information & $1-5$ \\
\hline Use of background music & Use / non-use of background music & 6 \\
\hline Why use? & Reasons of use/ non-use of background music & 7,8 \\
\hline \multirow{2}{*}{ How used? } & Music genres, sources, & $9-14$ \\
& Consideration, advantages of use of background music & $15-18$ \\
\hline
\end{tabular}

Table 3. Interview Participants and Interview Foci

\begin{tabular}{cccccc}
\hline Teacher & Age & $\begin{array}{c}\text { Teaching } \\
\text { experiences, } \\
\text { years }\end{array}$ & $\begin{array}{c}\text { Type of } \\
\text { workplace } \\
\text { institution }\end{array}$ & $\begin{array}{c}\text { Age group(s) } \\
\text { in the classrooms, } \\
\text { years }\end{array}$ & $\begin{array}{c}\text { Professional } \\
\text { certification level }\end{array}$ \\
\hline A & 26 & 2 & Daycare & 3 & *D I \& K II \\
\hline B & 34 & 10 & Daycare & Mixed(3\&4) & D I \& K II \\
\hline C & 28 & 5 & Daycare & 5 & D I \& K II \\
\hline D & 34 & 10 & Private K & 3 & K I \\
\hline E & 32 & 8 & Private K & 5 & K I \\
\hline F & 28 & 4 & Private K & 4 & K II \\
\hline G & 31 & 7 & Montessori K & 5 & K II \\
\hline H & 25 & 3 & Montessori K & 4 & K II \\
\hline I & 29 & 6 & Montessori K & 3 & K II \\
\hline L & 25 & 2 & Montessori K & 3 & K II \\
\hline M & 35 & 13 & Montessori K & 5 & K II \\
\hline N & 24 & 2 & Montessori K & 4 & \\
\hline Daycar & & & & & \\
\hline
\end{tabular}

$* \mathrm{D}=$ Daycare centre certificate, $\mathrm{K}=$ Kindergarten certificate 
The interview participants were twelve teachers from early childhood institutions representing children drawn from three age groups (3-5y) in both of daycare and kindergarten in Seoul, the capital city of South Korea. The institutions were Montessori kindergarten, private kindergarten and daycare centres in Seoul. Although Montessori kindergarten are also private, their programme is more specialized compared to other private kindergartens and daycare centres. All interviewee had teaching certification, including daycare and kindergarten at Level II and above. Three teachers were from a private kindergarten and three others from a daycare centre. Six teachers were from one Montessori kindergarten where background music in children's Montessori work time was a rule of the institution. Thus, this biased the data somewhat in that most interviewees were using background music in their free-play time.

\section{Procedure}

The online survey opened with a consent letter page, where the participants indicated their agreement before proceeding to the main survey instrument. All raw data were transferred to SPSS 19.0 (Datasolution Inc., Seoul, South Korea). The first author conducted descriptive analyses to examine the frequencies and dispersions of responses to each survey question. In order to find statistical differences in the use of music, based on institution types, teachers' professional experiences, and classroom age group, the author conducted chi-square analyses. Subsequently, as mentioned earlier, in order to acquire a more detailed understanding through the voices of the teachers, the author interviewed twelve teachers drawn from three preschools. Each participant was interviewed three times for 30 minutes in their institutions over a period of two months. This allowed a sequence of initial introduction and opening discussion, followed by more detailed interviews and checking of responses back. For example, the main questions were similar in each of the three interviews, with the first interview more focused on establishing rapport. In the second and third interviews, the first author sought more detail, with additional follow-up questions based on the first interview, and also checked for the unclear answers. There were a total of $n=36$ interviews from the twelve interviewees. The interview locations were their classrooms after formal school hours at the teachers' convenience. The interview questions were basically the same as those used in the earlier survey, but presented in a more 
semi-structured manner in order to elicit a wider range and depth of response. Analyses of interview data were undertaken by transcribing the recorded audio data. The data from interview audio files was reviewed repeatedly and categorized according to the themes in the survey questionnaire.

\section{Results}

\section{(a) Use of Background Music and (b) Why or Why not}

The survey responses for the use (or not) of background music in free-play time indicated a slight bias towards use, i.e. $54 \%$ of responses indicated use of background music during free-play time, whereas $46 \%$ did not. There were no statistical differences in the use of music according to location, i.e., kindergarten/daycare $(\chi 2=.787, p=.375)$, nor in responses by teachers' years of professional experiences $(\chi 2=1.01, \mathrm{p}=.894)$. Korea early years provision is usually divided to two groups: very young children ( 0 to 2 years old children) and young children ( 3 to 5 years old children). Consequently, the author conducted chi-square analyses by age of children and setting. There were significant differences in responses between the 0 to 2 year age group and the 3 to 5 year age group ( $\chi^{2}$ $=5.568, \mathrm{p}=.018)$. Overall, teachers of younger children $(0-2 \mathrm{y})$ were much more likely to use background music (by a ratio of $>2: 1$ ). In contrast, teachers of older children were more equally divided between use and non-use, with a slight majority favouring the latter (i.e., $\mathrm{n}=41$ for use, versus $\mathrm{n}=47$ for non-use).

As to the reported reasons for why teachers did not use background music, $n=59$ teachers responded and the prime reasons were related to a perception that (a) their classrooms were already noisy and that background music would either exacerbate the problem and/or (b) be distracting for the children (see Table 4).

In contrast, those teachers who were in favour of background music $(n=68)$ responded that this related to (a) their perceptions of children's liking for background music, and that this would (b) facilitate children's free-play and (c) create a positive, pro-active and energising mood in the classroom. They also expressed (d) a personal preference for music and (e), in contrast to those who reported against the use of background music, saw music 
as actually also having a calming influence (despite its energising potential) (Table 5).

Table 4. Teachers' ( $n=59)$ Responses to the Question: Why Do You not Use Background Music?

\begin{tabular}{|c|c|c|c|}
\hline & $* 1-2$ & 3 & $4-5$ \\
\hline Noise problems in the classroom & $36(61)$ & $11(19)$ & $13(22)$ \\
\hline Background music is distracting & $23(39)$ & $13(22)$ & $23(39)$ \\
\hline $\begin{array}{l}\text { It is a rule of my preschool } \\
\text { (Principal's recommendation) }\end{array}$ & $2(3)$ & $1(2)$ & $56(95)$ \\
\hline I don't like music personally & $1(2)$ & $4(7)$ & $54(92)$ \\
\hline Children don't want to listen to the music & $0(0)$ & $11(19)$ & $48(81)$ \\
\hline
\end{tabular}

$* 1=$ very much agree; $2=$ agree $3=$ somewhat agree; $4=$ disagree; $5=$ very much disagree

Table 5. Teachers' (n=68) Responses to the Question: Why Do You Use Background Music?

\begin{tabular}{lccc} 
& & & $\mathrm{N}(\%)$ \\
\hline Children like to have background music playing & $* 1-2$ & 3 & $4-5$ \\
\hline Facilitating for children's play & $59(87)$ & $9(13)$ & $0(0)$ \\
\hline To create a pro-active, energising mood in the classroom & $58(85)$ & $9(13)$ & $1(2)$ \\
\hline I like music personally & $58(85)$ & $7(10)$ & $3(4)$ \\
\hline To calm the classroom & $52(77)$ & $13(19)$ & $3(4)$ \\
\hline The rule of preschools & $34(50)$ & $23(34)$ & $12(18)$ \\
\hline
\end{tabular}

$* 1=$ very much agree; $2=$ agree $3=$ somewhat agree; $4=$ disagree; $5=$ very much disagree

Interviews with the twelve teachers revealed similar findings as reported above in the survey data. Eleven teachers used background music and thought that music helped children's concentration with their work and also calmed their mood. Eight teachers reported that they themselves responded positively to having background music, such as feeling calmer. Teachers also reported that children recognized the choice of music repertoire from previous experience.

When I play background music, children become quieter, thus reducing classroom noise...

(M teacher, 1 st interview) 
When playing music, I also feel relaxed and calmer... Sometimes children identify the type of instrument or the songs...

(N teacher, 1st interview)

I use background music in order to help the children concentrate better on their work, because this institution has a Montessori programme. Therefore, there are quieter activities in free-play time, compared to other pre-schools...also, the Principal of our school recommends playing background music in the playtime

(N teacher, 3rd interview)

One teacher did not use background music in order to prevent disruption of the children's play. She said that background music could interrupt some children's work, since a few children would respond to familiar songs promptly, in different ways, such as dancing and singing.

I tried to play music several times, but now I hardly play music during free-play time. If children have difficulties learning a new song, I tried to play the songs in advance... Children sang the familiar songs along with the background music and sang in front of the speaker. At that time, I felt it could be an interruption for children's play. After that, I did not play background music... Several children responded to the music too loudly, so it caused an interruption to others' work. I tried to play calm Classical music to reduce children's chatting, but they were not interested in the music, so they talked louder.

(D teacher, 1st interview)

Some teachers also reported that they had experience of both using and not using background music. They noticed differences between free-play with and without music.

One day my computer battery died and the music suddenly stopped. Some children said to me "The music has stopped!", although I had not realised that. Sometimes music caused an increase in the children's chatting and they also talked louder....

(D teacher, 3rd interview)

I used background music at the beginning of a semester, but I currently cannot play music because the daily programme for five-year-old children means there is not enough [free-play] time [because of] events, field trips, special teacher classes.

(E teacher, 1st interview) 
I use background music especially to calm the mood of the class before the Summer vacation and after a new semester starts. Sometimes, I play background music for pre-learning before introducing a difficult new song.

(E teacher, 2nd Interview)

\section{How Teachers Used Background Music}

Survey participants reported that they had acquired background music by downloading this from a music website, or bookstores, workshops or in teacher training programmes, and institutions for music education (in descending order) (Table 6).

Table 6. Teachers' Responses to the Question: How Do You Purchase Music?

\begin{tabular}{llll} 
& & $N(\%)$ \\
\hline Download from a music website & $* 1-2$ & 3 & $4-5$ \\
\hline Book store including internet book store & $57(84)$ & $3(4)$ & $8(12)$ \\
\hline At the workshop or teacher training programme & $19(28)$ & $21(31)$ & $15(22)$ \\
\hline Institution for music education & $16(24)$ & $11(16)$ & $41(60)$ \\
\hline
\end{tabular}

$* 1=$ very much agree; $2=$ agree $3=$ somewhat agree; $4=$ disagree; $5=$ very much disagree

Among teacher who used background music in free-play time, the majority of teachers $(60 \%)$ played background music all the way through during free- play time, and a few played it to start or close free- play time only (12\% and 3\%, respectively). The majority of teachers played children's songs and Classical music as background music; whereas no teachers reported playing K-pop or pop songs (Figure 1).

Amongst teachers who reported using background music, some teachers (19\%) used background music without lyrics, yet others (32\%) played songs with lyrics. More teachers (49\%) used both. In terms of tempo, most teachers used medium tempo music (81\%); slow music $(15 \%)$ was used more often than fast $(3 \%)$. There was similar usage between music with a fast and light mood (41\%), or a calm and quiet feeling (38\%).

When teachers chose background music, they took into account (a) emotional reasons related to the perceived mood of the music, (b) children's musical preferences, and (c) its relationship to educational themes. The next most important principles for music selection 
were (d) related to aesthetics, such as the perceived beauty of a melody and context of lyrics. However, (e) teachers' personal preferences and the relative perceived quality of the music were less important reasons (Table 7).

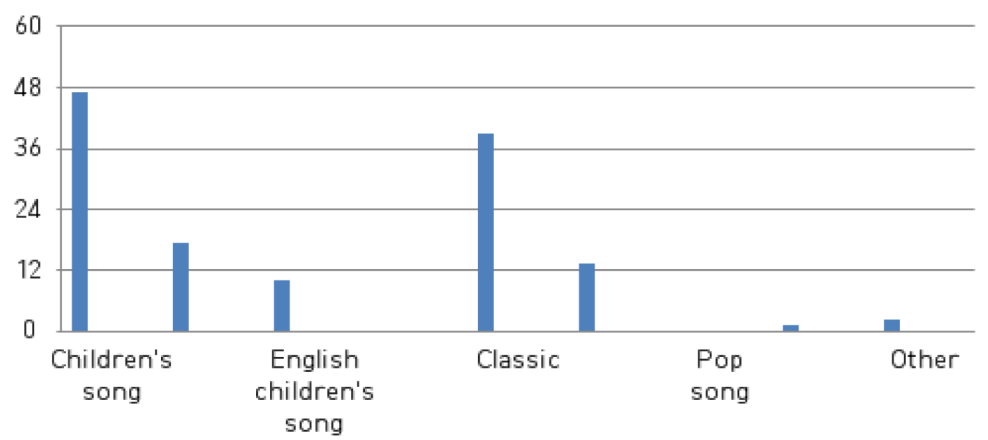

Figure 1. The Various Music Genres Used as Background Music

Table 7. Teachers' Responses to the Question: How Important Is Each of These Factors When You Choose Background Music? $\mathrm{N}(\%)$

\begin{tabular}{lccc}
\hline & $* 1-2$ & 3 & $4-5$ \\
\hline Mood of music & $64(94)$ & $4(6)$ & $0(0)$ \\
\hline Children's preference & $58(85)$ & $9(13)$ & $1(2)$ \\
\hline Relation to educational theme & $56(82)$ & $9(13)$ & $3(4)$ \\
\hline Beauty of melody & $55(81)$ & $13(19)$ & $0(0)$ \\
\hline Content of lyrics & $54(79)$ & $10(15)$ & $4(6)$ \\
\hline Teachers' preference & $48(71)$ & $20(29)$ & $0(0)$ \\
\hline Quality of playing & $40(59)$ & $25(37)$ & $3(4)$ \\
\hline
\end{tabular}

*1 $=$ very important; $2=$ important $3=$ somewhat important; $4=$ not important; $5=$ not at all

In terms of the equipment used for playing background music, participants used a $\mathrm{CD}$ player $(62 \%)$, computer $(35 \%)$ and MP3 player (3\%). As mentioned above, the teachers played background music for free-play time in medium or soft dynamics. No teacher played music loudly.

When asked about the advantages of playing background music, the majority of teachers in favour responded that background music during free-play time was helpful to teach songs or content-related themes. Some teachers considered children's preferences, 
activating children's play, and to calm the mood in the classroom as merits for using background music (Table 8 ).

Table 8. Teachers' Responses to the Question: What Are the Benefits of Background Music During Free-play Time? $\mathrm{N}(\%)$

\begin{tabular}{llll}
\hline & $* 1-2$ & 3 & $4-5$ \\
\hline Children like to play music & $63(93)$ & $5(7)$ & $0(0)$ \\
\hline Helps to teach songs or content related themes & $62(91)$ & $6(9)$ & $0(0)$ \\
\hline Activates children's play & $59(87)$ & $7(10)$ & $2(3)$ \\
\hline Calms the mood in the classroom & $51(75)$ & $15(22)$ & $2(3)$ \\
\hline
\end{tabular}

$* 1=$ very much agree; $2=$ agree $3=$ somewhat agree; $4=$ disagree; $5=$ very much disagree

There are similar findings in the results of the interviews regarding how to use background music. Most teachers reported using Classical music, easy listening music and children's songs at soft or medium loudness levels. Teachers reported used 'calming' music to reduce children's talking, or to promote a calm mood. They also used children's songs in order to expose the children to a new song in advance, before they taught this formally. Most teachers played music using computers and acquired the material from music websites. Teachers also shared background music lists from a teacher website. Teachers chose music lists related to educational themes or other teachers' recommendation on their teacher website.

I tried to play various styles of music. When I played calm classical music, children's play becomes very quiet and they focus more on their play... When I play natural sounds, children listen to the sounds very carefully. When I play bright music, they sing along with the song or engage in play more actively.

(F teacher, 2nd interview)

Overall, there was a similar trend in teachers' responses about why and how to use background music and its possible benefits between the survey and interview data, although these were not the same participants. Teachers presented their experiences and impression about playing background music in free-play time, and the content of interview expanded the survey results. 


\section{Discussion and Conclusion}

\section{Implications for Early Childhood Music Education}

The present study investigated teachers' perceptions about the use of background music in free-play time. The main concerns were how many teachers used background music during free-play time, why there are differences in usage and how music was used. The results offer several implications for early childhood music education.

The use or absence of background music during free-play time were not significantly different, but rather had similar dispersions, with a slight bias towards use. Although teachers' use or absence of background music were different, most of them presented their perception about the importance of children's play. Teachers who used background music aimed to facilitate children's play and/or consider children's preferences; whereas, teachers who did not use it, did not want to interrupt the children's play by creating a noisy environment and/or considered children's preference for no music.

Furthermore, the study investigated in more detail how teachers use background music. Regarding the sources of background music teachers being used, the majority of teachers downloaded examples from a music website. Teachers played children's songs and classical music as background music, but no teachers played K-pop or pop songs. Teachers used music with and without lyrics, with a preferred bias towards a medium tempo and lighter mood, or music with a calm and quiet feeling.

When teachers chose background music, they reported that they considered the mood of the music, the children's preference and its possible relationship to a topical educational theme. When asked the merits of playing background music, the majority of teachers responded that background music during free-playtime is seen as helpful to teach songs or content-related themes. The consideration for selection and the merit of background music teachers perceived were consistent.

Overall teachers' perception of this study corresponds with the previous research. Many studies indicated the diverse effects of background music with either a positive impact (Carlson et al., 2004; Schellenberg, Nakata, Hnter, \& Tamoto, 2007) or/and a negative impact (Anderson \& Fuller, 2010; Avila, Furnham, \& McClelland, 2011; Boyle \& Coltheart, 1996; Dartt, 2009). In the present study teachers were aware of the potential impacts of 
background music and appeared to make their choices (for/against) based on rational reasons and craft knowledge. A previous study (Dartt, 2009) indicated that 3-5-year-olds paid less attention in play tasks with background music than during a pretest with no music. Those results support teachers' perceptions to not using background music in the present study. However, the Dartt study was conducted in an individual play setting rather than free-play time in a classroom setting. The teachers' response of not using background music in this study may be viewed as evidence that the use of background music may be perceived by some interrupt children's play or aggravate teachers' stress by creating a noise problem. On the other hand, teachers who used background music perceived the music as relaxing and facilitating a positive mood. Other previous studies are supportive of such a stance concerning background music (Hallam et al., 2002; Love \& Burns, 2007), such as related to music's power for emotional arousal and release (Egermann et al., 2015; Sims Cecconi-Roberts, 2005) and to influence mood positively (Eich \& Forgas, 2003). Further study should examine the real effect of background music on children's play in a classroom setting, in order to find out whether teachers' perceptions of background music is evidence based or overestimated.

According to the results of the present study, there were similarities in the reasons to using/not using background music and the merits of its use. The responses indicated that, in general, teachers made child-centered choices, such as considering the young children's preference and the likely impact on their free-play. Also, the kinds of music played were not pop songs, but either classical or children's songs. The findings were similar to those in a previous study (Lee, 2008), but somewhat different from those of previous studies which used pop and jazz music as well as children's songs (Sims \& Cecconi-Roberts, 2005). Further in-depth inquiry using interview and observation to explore why teachers use children's songs is recommended. Grebennikov (2006) indicated that most teachers in early childhood institutions are exposed to noise at a very dangerous level and that music was one of the noise sources. Further research to measure the noise level in preschools with music/without music is suggested because the health implications of noise level are very important consideration for young children and teachers. 


\section{Limitations and Suggestions for Further Research}

This study investigated the use of background music in free-play time only based on teachers' perceptions; therefore it has several limitations. Since the response of how to use background music is based on the teachers' perceptions, the responses are personally reflective, such as with regard to loudness levels, musical genres and tempi. Further research should be undertaken to investigate the degree of match between teachers' perceptions and their local reality to extend the dataset reported here which derived from an online survey and an off line interview. However, for practical reasons, the participants of the interviews were different from the anonymous survey participants. Most interviewees reported favourably on the use of background music because the majority were from Montessori kindergarten where they played background music throughout their daily schedule as the custom of the institution. A future study should be conducted involving an equal proportion of teachers who did not use background music.

The effect of background music on children's play may differ according to children's ages and the nature of the preschool programmes. Further research into the effect by comparing children's age or type of early childhood programmes is suggested.

The amount of free-play time has decreased in early childhood institutions in South Korea due to parents' requests for special activity classes such as English, music, or physical education. Nevertheless, sufficient free-playtime and quality absorbing opportunities should be guaranteed in early childhood institutions for a developmentally appropriate educational environment (Bredekamp \& Copple, 1997; Young, 2016).

Although there are several limitations, this study provides a basic insight into teachers' perceptions about the use of background music in free-playtime and highlights the importance of free-play time during the early years.

\section{References}

Anderson, S. A., \& Fuller, G. B. (2010). Effect of music on reading comprehension of junior high school students. School Psychology Quarterly, 25(3), 178-187.

Adachi, M., \& Trehub, S. E. (2012). Musical livers of infants. In G. McPherson \& G. Welch 
(Eds.), The Oxford handbook of music education (pp. 229-247). New York, NY: Oxford University Press.

Avila, C., Furnham, A., \& McClelland, A. (2011). The influence of distracting familiar vocal music on cognitive performance of introverts and extraverts. Psychology of Music, 40(1), 84-93.

Barrett, M. (2016). Attending to "culture in the small": a narrative analysis of the role of play, thought and music in young children's world-making. Research Studies in Music Education, 38(1), 41-54.

Boyle, R. \& Coltheart, V. (1996). Effects of irrelevant sounds on phonological coding in reading comprehension and short-term memory. The Quarterly Journal of Experimental Psychology, 49(2), 398-416.

Bredekamp, S., \& Copple, C. (1997). Developmentally appropriate practice in early childhood programs. Washington, DC: National Association for the Education of Young Children.

Campbell, L., Campbell, B., \& Dickenson, D. (2004). Teaching and learning through multiple intelligences ( $3^{\text {rd }}$ ed.). Boston, MA: Pearson Education, Inc.

Carlson, J., Hoffman, J., Gray, D., \& Thompson, A. (2004). A musical interlude: Using music and relaxation to improve reading performance. Intervention in School and Clinic, 39(4). 246-250.

Connolly, D., J. Dockerell, J., Shield, B., Conetta, R., Cox, T.(2013). Adolescents' perceptions of their school's acoustic environment: The development of an evidence based questionnaire. Noise \& health, 15(65), 269-80.

Chi, S., Hong, H., Lee, J., \& Chang, M. (2015). Constructing the model for the integrated early childhood education and care. Early Childhood Education Journal, 35(5). 5-29.

Dartt, K. M. (2009). Effects of background music on preschoolers' attention. Unpublished doctoral dissertation. University of North Texas, Texas, U.S.

Egermann, H., Fernando, N., Chuen, L., \& McAdams, S. (2015). Music induces universal emotion-related psychophysiological responses: comparing Canadian listeners to Congolese Pygmies. Frontiers in Psychology. 7. doi: 10.3389/fpsyg.2014.01341

Eich, E., \& Forgas, J. P. (2003). 'Mood, cognition, and memory', In A.F. Healy and R.W. Proctor (Eds.), Handbook of psychology: Experimental Psychology, 4(pp. 61-83). New 
York: Wiley.

Grebennikov, L. (2006). Preschool teachers' exposure to classroom noise. International Journal of Early Years Education, 14(1), 35-44.

Godeli, M. R., Santana, P. R., Souza, V. H., \& Marquetti, G. P. (1996). Influence of background on preschoolers' behavior: A naturalistic approach. Perceptual and Motor Skills, 82, 1123-1129.

Golden, M. \& Frank, T. (2000). Further acoustical analysis of infant/toddler rooms in daycare centres. Journal of the Acoustical Society of America, 107(5), 2833-2833.

Gruhn, W., \& Rauscher, F. (2002). The neurobiology of music cognition and learning. In R. Clowell (Eds.), MENC handbook of musical cognition and development (pp. 40-72). New York: Oxford University Press.

Hallam, S., Price, J., \& Katsarou, G. (2002). The effects of background music on primary school pupils' task performance. Educational Studies, 28(2), 111-122.

Johansson, R., Holmqvist, K., Mossberg, F., \& Lindgren, M. (2011). Eye movements and reading comprehension while listening to preferred and non-preferred study music. Psychology of Music, 40(3), 339-356.

Jung, S. K., \& Ahn, S. H. (2006). The relationship between peer play behavior and learning behaviors for low income preschool children. Journal of Future Early Childhood Education, 3(4), 217-236.

Kenneth, R. G. (2007). The Importance of play in promoting healthy child development and maintaining strong parent-child bonds. Pediatrics, 119(1), 182-191.

Kim, \& Lee, (2005). The Survey Study on Extracurricular Activities in Infant's Educational Institutes. Asian Journal of Child Welfare and development, 3(3). 71-84.

Kristiansen, J., Lund, S., Persson, R., Challi, R., Lindskov, J., Nielsen, P., Larsen, P., \& Toftum, J. (2016). The effects of acoustical refurbishment of classrooms on teachers' perceived noise exposure and noise-related health symptoms. International Archives of Occupational and Environmental Health, 89(2), 341-350.

Lee, J. W. (2015). A critical review on the current policy of integration early childhood education and care in Korea. Korea Journal of Early Childhood Education, 35(6), 221-240.

Lee, Y. (2008). Music practice and teachers'needs for teaching music in public preschools 
of South Korea. Unpublished doctoral dissertation. University of Missouri-Columbia, Missouri, U.S.

Love, A., \& Burns, M. S. (2007). "It's a hurricane! It's hurricane!" Can music facilitate social constructive and sociodramatic play in a preschool classroom? The Journal of Genetic Psychology, 167(4), 383-391.

Mattar, J. (2013). The effect of Mozart's music on child development in a Jordanian kindergarten. Education, 133(3), 370-377.

Ministry of Education \& Ministry of Health and Welfare. (2013). 3 - 5 Nuricurricum. Korea: Ministry of Education \& Ministry of Health and Welfare.

Rauscher, F. H., Shaw, G. L., \& Ky, K. N. (1993a). Listening to Mozart enhances spatial-temporal reasoning: Towards a neurophysiologic basis. Neuroscience Letters, 185, 44-47.

Rauscher, F. H., Shaw, G. L., \& Ky, K. N. (1993b). Music and spatial task performance. Nature, 365, 611 .

Riber, M. (1965). The effect of music on the activity level of children. Psychonomic Science, 3(8), 325-326.

Saarikallio, S. H. (2008). Music in mood regulation: initial scale development. Musicae Scientiae, 12(2), 291-309.

Schellenberg, E. G., Nakata, T., Hnter, P.G., \& Tamoto, S. (2007). Exposure to music and cognitive performance: tests of children and adults. Psychology of Music, 35(1), 5-19.

Shield, B., Greenland, E., Dockrell, J. (2010). Noise in open plan classrooms in primary schools: A review. Noise and Health, 12(49), 225-234.

Sims, W. L., \& Cecconi-Roberts, L. (2005). Availability and use of recorded music in selected prekindergarten classrooms. Missouri Journal of Research in Music Education, 52, 58-76.

Song, S. J. (2012). Study on extracurricular activities by young children's age and their parents' perception at private child-care centre: Focused on Yahgcheon-Gu child-care centres. Unpublished master' thesis. Myoung-Ji University. Seoul, South Korea.

Sodersten, M., Granqvist, S., Hammarberg, B., \& Szabo, A. (2002). Vocal behavior and vocal loading factors for preschool teachers at work studied with binaural DAT recordings. Journal of Voice, 16(3), 356-371. 
Tronick, E. (2007). The neurobehavioral and socio-emotional development of infants and children. London, UK: Norton.

Welch, G. F. (2006). The musical development and education of young children. In B. Spodek \& O. Saracho (Eds.), Handbook of Research on the Education of Young Children(pp. 251-267). Mahwah, N.J.: Lawrence Erlbaum Associate Inc.

Young, S. (2002). Young children's spontaneous vocalizations in free-play: observations of two- to three- year-olds in a day-care setting. Bulletin of the Council for Research in Music education, 152, 43-53.

Young, S. (2016). Early childhood music education research: An overview. Research Studies in Music Education, 38(1), 9-21.

Ziv, N., \& Goshen, M. (2006). The effect of 'sad' and 'happy' background music on the interpretation of a story in 5 to 6-year-old children. British Journal of Music Education, 23(3), 303-314. 